\title{
Testicular Morphological and Ultrasonographic Characterization of Male Gray Brocket Deers (Mazama gouazoubira) in Different Reproductive Status*
}

\author{
Duanny Murinelly de Souza Cunha', Mírley Barbosa de Souza', Bruna Farias Brito', Vítor Lima Torres', \\ Thalles Gothardo Pereira Nunes', Samuel Salgado Tavares², Daniel de Araujo Viana³, \\ Lúcia Daniel Machado da Silva', Leda Maria Costa Pereira' \& Dárcio Ítalo Alves Teixeira'
}

\begin{abstract}
Background: Gray brocket deer (Mazama gouazoubira) populations have been declining due to human intervention. Yet, only a few studies have assessed ultrasonographic testicular characteristics in cervids. Considering the relevance of monitoring testicular size, blood flow, and parenchyma, the present study aims to establish baseline information on scrotal circumference, testicular volume, and spectral Doppler parameters, to describe differences among adult male gray brocket deer in different reproductive status, and to correlate ultrasound parameters with testes size measurements.

Materials, Methods \& Results: Six adult male gray brocket deers were used in the study. Scrotal circumference and testicular volume were measured. B mode ultrasound images of testes (longitudinal and cross-sectional views) and epididymes were subjected to computer-assisted analysis, obtaining the numerical pixel values (NPV) and pixel standard deviation (PSD). Using spectral Doppler, supratesticular artery blood flow velocities (peak systolic velocity - PSV, end diastolic velocity EDV, time-average maximum velocity - TAMAX, resistivity - RI and pulsatility indices - PI) were obtained. Semen was analyzed through total motility, vigor, and concentration tests. Three animals were normospermic (F+ group) and three were oligo/azoospermic (F- group). Groups were compared using were compared using a one-way ANOVA or KruskalWallis followed by Student-Newman-Keuls (SNK) test. Ultrasound parameters were correlated to testes size parameters using Pearson's correlation for parametric variables and Spearman's correlation for non-parametric variables. F+ group presented significantly higher scrotal circumference $(14.57 \pm 1.19 \mathrm{~cm})$, testicular volume $(26.18 \pm 4.94 \mathrm{~cm} 3)$, and testes cross-sectional NPV $(69.88 \pm 24.00)$ and PSD $(10.78 \pm 3.42)$ than group F- (NPV: $28.26 \pm 13.75$, PSD: $6.70 \pm 1.84)$. No significant differences were observed between the groups regarding the spectral Doppler ultrasound parameters. Significant correlations were observed between scrotal circumference and longitudinal $(\mathrm{r}=0.76)$ and cross-sectional testes NPV $(\mathrm{r}=$ $0.89)$, and testicular volume was correlated with longitudinal $(\mathrm{r}=0.78)$ and cross-sectional testes NPV $(\mathrm{r}=0.91)$ and with cross-sectional testes PSD $(\rho=0.82)$.

Discussion: Increased testicular echogenicity (higher NPV) has been positively associated with improved testicular growth, cell population expansion, inner and outer seminiferous tubules diameter, spermatids percentages and testis weight. In addition, more heterogenous testes (higher PSD) were associated with higher sperm output. It was suggested that the animals in group F- had compromised testicular development and spermatogenesis. The correlation observed between testes NPV and scrotal circumference was proposed to be associated with seminiferous tubules impairment. The F- group showed lower testicular volume, NPVs and PSDs in cross-sectional testicular images, suggesting higher protein levels and lower lipid contents were present in their parenchyma, influencing in testicular echogenicity and echotexture. No differences in spectral Doppler parameters were observed between the two groups. Also observed in stallions. However, PSV, EDV, TAMAX could be potential infertility indicators in other mammalians. These different results may be due to different locations of the evaluated vessel, species and techniques, age, ambient temperature, pathological conditions, and anaesthesia. Thus, it is suggested that scrotal circumference, testicular volume, and testes NPV are good indicators of male reproductive health in gray brocket deer and may help with better male selection in the species.
\end{abstract}

Keywords: Cervidae, scrotal circumference, pixel intensity, dopplervelocimetry.

DOI: $10.22456 / 1679-9216.98311$

Received: 4 August 2019

Accepted: 25 November 2019

Published: 12 December 2019

"Article based on a Thesis submitted by the first author in partial fulfillment of requirements for the Master's degree. Programa de Pós-graduação em Ciências Veterinárias (PPGCV), State University of Ceará (UECE), Fortaleza, CE, Brazil. ${ }^{1}$ Faculty of Veterinary (FAVET), UECE, Fortaleza. ${ }^{2}$ Aba-Yby Conservation Institute - Ecopoint Environmental Education Ltd., Fortaleza. ${ }^{3}$ Pathovet Laboratory, Fortaleza. CORRESPONDENCE: D.I.A. Teixeira [darcio.teixeira@uece.br]. Av. Dr. Silas Munguba n.1700. CEP 60714903 Fortaleza, CE, Brazil. 


\section{INTRODUCTION}

Although Mazama gouazoubira is globally classified as of "least concern" by the International Union for Conservation of Nature, its populations are decreasing due to the extension of human communities [10]. Assisted reproduction programs are important tools for species conservation [36], thus improved diagnostic techniques may help with male selection, increasing conservation programs efficiency [46].

Ultrasonography has proven to be a valuable, and non-invasive diagnostic technique for assessing genital macroscopic morphology, pathology and testicular blood flow in several mammalian species $[3,29,39,41]$. Testes pixel intensity has been used to objectively identify differences in testicular parenchyma during sexual development [6], and after scrotal insulation [4]. Also, the Doppler technique detected blood flow changes in testicular artery in different seasons [27], and in males with fertility disorders [29,34]. Yet, few studies have investigated male deer reproductive system $[23,46]$.

Moreover, estimating scrotal circumference and testicular volume is a cheap, non-invasive method, widely used in several deer species [13,15,24,31,32], essential to breeding soundness examination in domestic ruminants [1,5] and associated with fertility in rams [19] and in bulls [42].
Therefore, considering the poor literature about ultrasound and testis size description in gray brocket deer, the aims of this study were to establish baseline information on scrotal circumference, testicular volume, and spectral Doppler parameters for the species; to describe differences found between deer in different reproductive status; and to correlate ultrasound parameters with testes size measurements.

\section{MATERIALS AND METHODS}

Animals

Six adult male gray brocket deer (M. gouazoubira) were used. The evaluations were performed from January to December 2018. Two evaluations were completed on each male, except on male 6 , which was evaluated once $(n=11)$. The males were housed in private institutions: two were at Aba-Yby Conservation Institute - Ecopoint Environmental Education Ltd. (Fortaleza, CE, Brazil) and four were at Claro Commercial Wild Animal Breeding Farm (Caucaia, CE, Brazil). The males were subjected to the usual management of each institution above. At Claro Farm, the males were fed equine food, grass (Cybodon dactylon or Brachiaria sp.) and roots (e.g. carrots and yuca) daily. At Aba-Yby Institute, males were offered ovine food, fruits, and grass daily. At both institutions, the males received water ad libitum. More information concerning the animals is provided in Table 1 .

Table 1. All data about the six gray brocket deer (Mazama gouazoubira) used in the present study.

\begin{tabular}{ccccccc}
\hline Male & City - State & Age & Weight $(\mathrm{kg})^{*}$ & Proved fertility & Housed with female & Origin/born \\
\hline Male 1 & Fortaleza, CE & 3 years & 14 & No & No & Captive \\
Male 2 & Caucaia, CE & 5 years & 15 & Yes & Yes & Captive \\
Male 3 & Caucaia, CE & 11 years & 15 & Yes & Yes & Captive \\
Male 4 & Fortaleza, CE & 3 years & 15.6 & No & Yes & Captive \\
Male 5 & Caucaia, CE & 1 year & 15 & No & Yes & Captive \\
Male 6 & Caucaia, CE & 3 years & 20 & No & Yes & Captive \\
\hline
\end{tabular}

*approximately

\section{Physical evaluation}

Firstly, all males were sedated using 5 to 10 $\mathrm{mg} / \mathrm{kg}$ ketamine hydrochloride $\left(\text { Cetamin }{ }^{\circledR}\right)^{1}$ and 0.5 to $1.5 \mathrm{mg} / \mathrm{kg}$ xylazine hydrochloride (Xylazine $10 \%()^{2}$, both injected intramuscularly $[16,18]$. Once the anesthesia took effect, a physical exam was per- formed. The testicular consistency was assessed by palpation. Scrotal circumference $(\mathrm{cm})$ was obtained using a measuring tape and testicular volume $\left(\mathrm{cm}^{3}\right)$ was obtained using a pachymeter and following the formula: $4 / 3 \times \varpi \times \mathrm{ABC}$, where $\mathrm{A}=$ width $/ 2, \mathrm{~B}=$ height/2, C = length/2 [15]. 


\section{Semen collection and general assessment}

Males were placed in a lateral decubitus position. The penis and prepuce were cleaned with saline solution (sodium chloride $0.9 \%$ ) and feces excess were removed from the rectum before introducing the probe with the electrodes positioned towards the prostatic surface. Semen was collected using an electroejaculator (Neovet Autoejac v2®) ${ }^{3}$. The procedure consisted of three sets of stimuli, with ten stimuli for each voltage: the first series starting with $4 \mathrm{~V}, 5 \mathrm{~V}$, and $6 \mathrm{~V}$; the second with $5 \mathrm{~V}, 6 \mathrm{~V}$, and $7 \mathrm{~V}$; and the third with $6 \mathrm{~V}, 7 \mathrm{~V}$, and $8 \mathrm{~V}$. Each series was separated by a $5 \mathrm{~min}$ interval rest [32]. The semen was collected in a $50 \mathrm{~mL}$ conical tube.

The microscopic parameters of total motility (0 - 100\%) and vigor (score 0 to 5) were assessed using a light microscope at 400x magnification. A $10 \mu \mathrm{L}$ fresh semen aliquot was added to a solution containing $2 \mathrm{~mL} 1 \%$ formaldehyde-saline $(0.9 \%$ sodium chloride solution). The concentration of sperm was quantified by counting the cells in five fields in a Neubauer chamber with a light microscope at 400x magnification [40]. Males 1, 2, and 4 were normospermic (high fertility potential; group F+). Male 3 appeared oligospermic in the first collection, but azospermic in the second collection; and males 5 and 6 were azoospermic on both analyses (low or no fertility potential; group F-).

\section{Ultrasound examination}

After the physical exam, the ultrasound assessment was performed using Mindray Z5Vet ${ }^{4}$. Males 1 to 5 were evaluated twice using the B mode technique ( $\mathrm{n}$ $=10$ ). Longitudinal and cross-sectional sections of testis and the epididymal tail were evaluated with a convex transducer under the following parameters: $5 \mathrm{MHz}$, gain of 64, depth of 16.6 (only on animal 1's first evaluation, depth was 9.2), frame rate of 56, B dynamic range of 110. Two images of each section were taken and saved. Afterwards, they were submitted to a computerized analysis (spot-meter technique) using the software

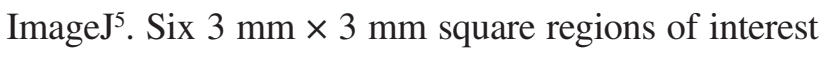
(ROI) in testis longitudinal view, four in testis crosssectional views, and two in epididymal images were selected (Figure 1). The mean pixel intensity (numerical pixel values, or NPV) and the pixel heterogeneity (pixel standard deviation, or PSD) were calculated inside those ROI in each image [37]. NPV were defined as gray-scale values of individual picture elements ranging from 0 (absolute black) to 255 (absolute white).

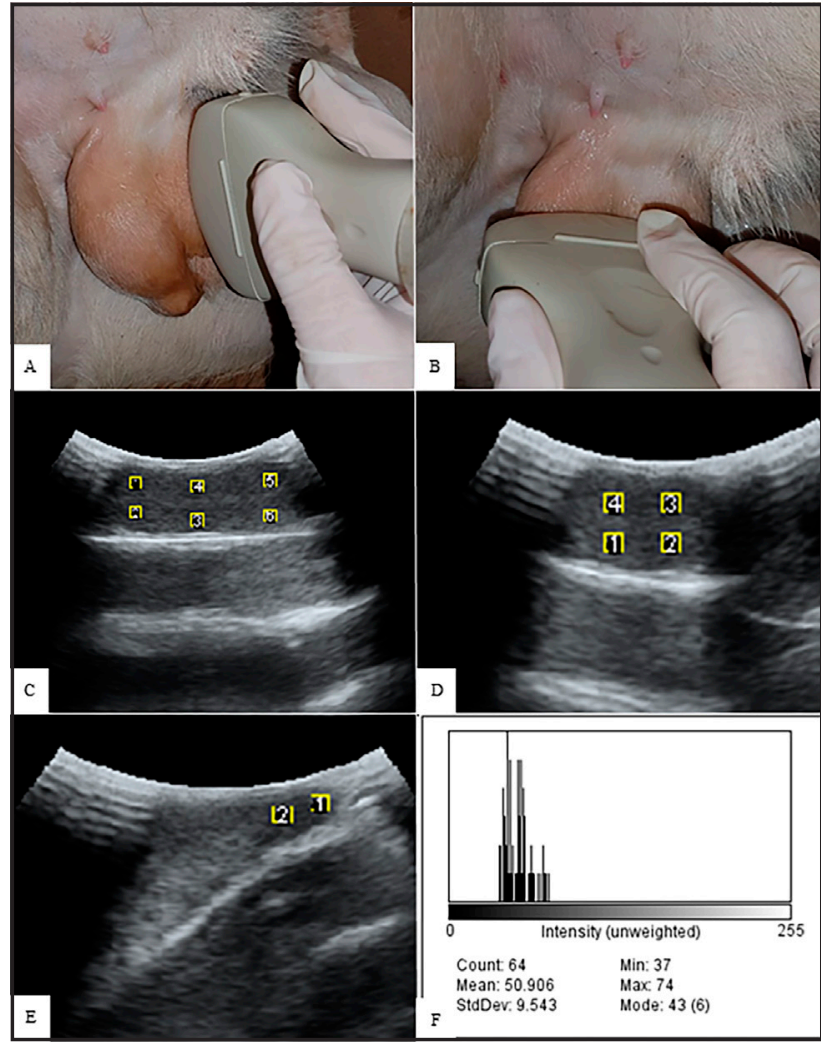

Figure 1. Computer-assisted analysis of the ultrasonographic images of gray brocket deer testes. A- Position of the transducer for visualizing a longitudinal section of the testis. B- Position of the transducer for visualizing a cross-sectional section of the testis. C- Spot-meter technique of pixel analysis: six open squares, $3 \times 3 \mathrm{~mm}^{2}$ in size, are placed on a longitudinal section of the ultrasonographic image of the testis. D- Four open squares, $3 \times 3 \mathrm{~mm}^{2}$ in size, are placed on a cross-sectional section of the ultrasonographic image of the testis. E- Two open squares, $3 \times 3 \mathrm{~mm}^{2}$ in size, are placed on a longitudinal section of the ultrasonographic image of the epididymis tail. F- Total pixel number (Count), mean NPV (Mean), standard deviation of NPV (StdDev), minimum value of NPV (Min), and maximum value of NPV (Max), most frequently occurring NPV within the selection (Mode) shown on a histogram.

Moreover, the spectral Doppler evaluation was performed on animals 1 to $6(n=11)$ using a linear transducer at $10 \mathrm{MHz}$. The angle of insonation used was set at $0^{\circ}$. At the region of the spermatic cord, the supratesticular artery flow was detected with color Doppler, the gate was positioned within the lumen of the vessel, and the equipment's algorithm package was used to calculate peak systolic velocity (PSV), end diastolic velocity (EDV), timeaverage maximum velocity (TAMAX), resistive index (RI) and pulsatility index (PI) during three waves of a cardiac cycle [34]. The same operator performed all examinations.

\section{Statistical analysis}

The data was analyzed using the statistical software R-project ${ }^{6}$, being submitted to the Cramer-Von 
Mises normality test and the Box-Cox homoscedasticity test. For comparison of means between groups $\mathrm{F}+$ and F-, the homogenous and normally distributed parameters (PSV, EDV, TAMAX, RI, NPVs of testes longitudinal and cross-sectional views, NPVs and PSDs of epididymis, PSDs of testes cross-sectional view, scrotal circumference, testicular volume) were compared using a one-way ANOVA followed by Student-Newman-Keuls (SNK) test. Logarithmic (Ln) transformation was performed on EDV, TAMAX, PSDs of testes cross-sectional view and epididymal PSDs. The non-parametric data (PI, PSDs of testes longitudinal view) were compared using a Kruskal-Wallis test followed by SNK test.

Ultrasound parameters were correlated to testes size parameters using Pearson's correlation for parametric variables (PSV, RI, NPVs of testes longitudinal and cross-sectional views, epididymal NPVs, scrotal circumference, and testicular volume) and Spearman's correlation for non-parametric variables (PI, EDV, TAMAX, PSDs of testes longitudinal and cross-sectional view, and epididymal PSDs). The results are expressed as mean \pm SD. Significance was set at $P<0.05$.

\section{RESULTS}

\section{Semen evaluation}

Males 1, 2 and 4 ejaculated in both collections and presented good quality semen (motility: $96.83 \pm$ $3.71 \%$; vigor: $4.41 \pm 0.38$; concentration: $94.08 \pm 65$. $04 \times 10 \mathrm{sptz} / \mathrm{mL})$. Male 3 ejaculated a low count sperm $(4 \times 10 \mathrm{sptz} / \mathrm{mL})$ with poor motility $(5 \%)$ and vigor $(1)$ on its first collection. On the second collection, it presented azoospermia. Males 5 and 6 were azoospermic in all collections. Male 6 presented intense germ cell epithelial degeneration in the histopathological exam which was compatible to testicular degeneration.

\section{Physical examination}

During physical examination, males 1, 2, 4, and 5 had normal consistence regarding their testes, but soft ones were identified in males 3 and $6 . \mathrm{F}+$ group showed significant wider scrotal circumference $(14.57 \pm 1.19 \mathrm{~cm}$; $P<0.05)$ and larger testis volume $(26.18 \pm 4.94 \mathrm{~cm} 3 ; P<$ 0.05 ) when compared to group F- (Scrotal circumference: $\left.12.06 \pm 0.62 \mathrm{~cm} ; 14.99 \pm 2.66 \mathrm{~cm}^{3} ; P<0.05\right)$.

\section{Ultrasound evaluation}

During the subjective B mode evaluation, it was observed that testes and epididymis were in the normal position, inside the scrotum. No abnormalities were noticed in the testicular and epididymal parenchyma. Testicular parenchyma had a smooth echotexture. The mediastinum was observed as a hyperechoic line (longitudinal view) or point (crosssectional view) in the center. The tunica albuginea was observed as a hyperechoic line surrounding the parenchyma and enclosing it and, the scrotum skin, as thicker hyperechoic line. The epididymis tail was slightly hypoechoic, comparing to testicular echogenicity, and it is also surrounded by tunica albuginea and the skin (Figure 2).

The waveform originated from supratesticular artery blood flow is shown in Figure 3. As shown in Table 2 , no significant differences were observed between the groups regarding the spectral Doppler ultrasound parameters: PSV (F+: $10.66 \pm 5.60 \mathrm{~cm} / \mathrm{s}, \mathrm{F}-:$ : $9.77 \pm 4.71$ $\mathrm{cm} / \mathrm{s}), \operatorname{EDV}(\mathrm{F}+: 5.59 \pm 2.17 \mathrm{~cm} / \mathrm{s}, \mathrm{F}-: 5.67 \pm 2.13 \mathrm{~cm} / \mathrm{s})$, TAMAX (F+: $0.38 \pm 2.62 \mathrm{~cm} / \mathrm{s}, \mathrm{F}-:=14 \pm 2.77 \mathrm{~cm} / \mathrm{s})$, PI (F+: $0.89 \pm 0.75$, F-: $0.53 \pm 0.12)$, and RI (F+: $0.40 \pm$ 0.10, F-: $0.38 \pm 0.06$ ). However, NPVs and PSDs of crosssectional testes images were higher on $\mathrm{F}+$ group (NPV: $69.88 \pm 24.00$, PSD: $10.78 \pm 3.42$ ) than F- group (NPV: $28.26 \pm 13.75$, PSD: $6.70 \pm 1.84)$. Longitudinal testis (F+: $66.16 \pm 30.66$, F-: $29.42 \pm 12.42)$ and epididymal images NPVs (F+: 42.28 \pm 14.32, F-: $24.95 \pm 6.78$ ) were not significantly different between the groups. Likewise, longitudinal testes $(\mathrm{F}+: 13.92 \pm 10.47$, F-: $7.71 \pm 3.41)$ and epididymal images PSDs (F+: $12.74 \pm 6.59$, F-: 10.77 \pm 8.31 ) showed no significant differences.

Table 2. B mode and spectral Doppler ultrasound parameters of normospermic $(\mathrm{F}+)$ and oligo/azoospermic (F-) gray brocket deer (Mazama gouazoubira).

\begin{tabular}{ccc}
\hline Parameter & $\mathrm{F}+$ & $\mathrm{F}-$ \\
\hline PSV $(\mathrm{cm} / \mathrm{s})$ & $10.66 \pm 5.60^{\mathrm{a}}$ & $9.77 \pm 4.71^{\mathrm{a}}$ \\
EDV $(\mathrm{cm} / \mathrm{s})$ & $5.59 \pm 2.17^{\mathrm{a}}$ & $5.67 \pm 2.13^{\mathrm{a}}$ \\
TAMAX $(\mathrm{cm} / \mathrm{s})$ & $6.38 \pm 2.62^{\mathrm{a}}$ & $7.14 \pm 2.77^{\mathrm{a}}$ \\
PI & $0.89 \pm 0.75^{\mathrm{a}}$ & $0.53 \pm 0.12^{\mathrm{a}}$ \\
RI & $0.40 \pm 0.10^{\mathrm{a}}$ & $0.38 \pm 0.06^{\mathrm{a}}$ \\
NPV (longitudinal testes) & $66.16 \pm 30.66^{\mathrm{a}}$ & $29.42 \pm 12.42^{\mathrm{a}}$ \\
NPV (cross-sectional testes) & $69.88 \pm 24.00^{\mathrm{a}}$ & $28.26 \pm 13.75^{\mathrm{b}}$ \\
NPV (epididymis) & $42.28 \pm 14.32^{\mathrm{a}}$ & $24.95 \pm 6.78^{\mathrm{a}}$ \\
PSD (longitudinal testes) & $13.92 \pm 10.47^{\mathrm{a}}$ & $7.71 \pm 3.41^{\mathrm{a}}$ \\
PSD (cross-sectional testes) & $10.78 \pm 3.42^{\mathrm{a}}$ & $6.70 \pm 1.84^{\mathrm{b}}$ \\
PSD (epididymis) & $12.74 \pm 6.59^{\mathrm{a}}$ & $10.77 \pm 8.31^{\mathrm{a}}$ \\
\hline a,b Different letters within a row show significant difference between groups \\
$(P<0.05)$ PSV= peak systolic velocity; EDV= end diastolic velocity; \\
TAMAX= time-average maximum velocity; PI= pulsatility index; RI= \\
$\begin{array}{ll}\text { resistivity index; NPV= numerical pixel values; PSD= pixel standard } \\
\text { deviation. Values (Mean } \pm \text { SD). }\end{array}$
\end{tabular}


Correlations between ultrasound and testis size parameters

Scrotal circumference was strongly correlated to testicular volume $(\mathrm{r}=0.88, P=0.0003)$. There was a moderate correlation between longitudinal testes NPVs and testicular size parameters such as scrotal circumference $(\mathrm{r}=0.76, P=0.01)$ and testicular volume $(\mathrm{r}=0.78, P=0.008)$. Cross-sectional testes NPVs were strongly correlated to scrotal circumference $(\mathrm{r}=$ $0.89, P=0.0006)$ and testicular volume $(\mathrm{r}=0.91, P$ $=0.0003)$. Cross-sectional testes PSDs were strongly correlated to testicular volume ( $\rho=0.82, P=0.004$ ), while the other ultrasound parameters showed no significant correlations with testicular size parameters, as displayed on Table 3.

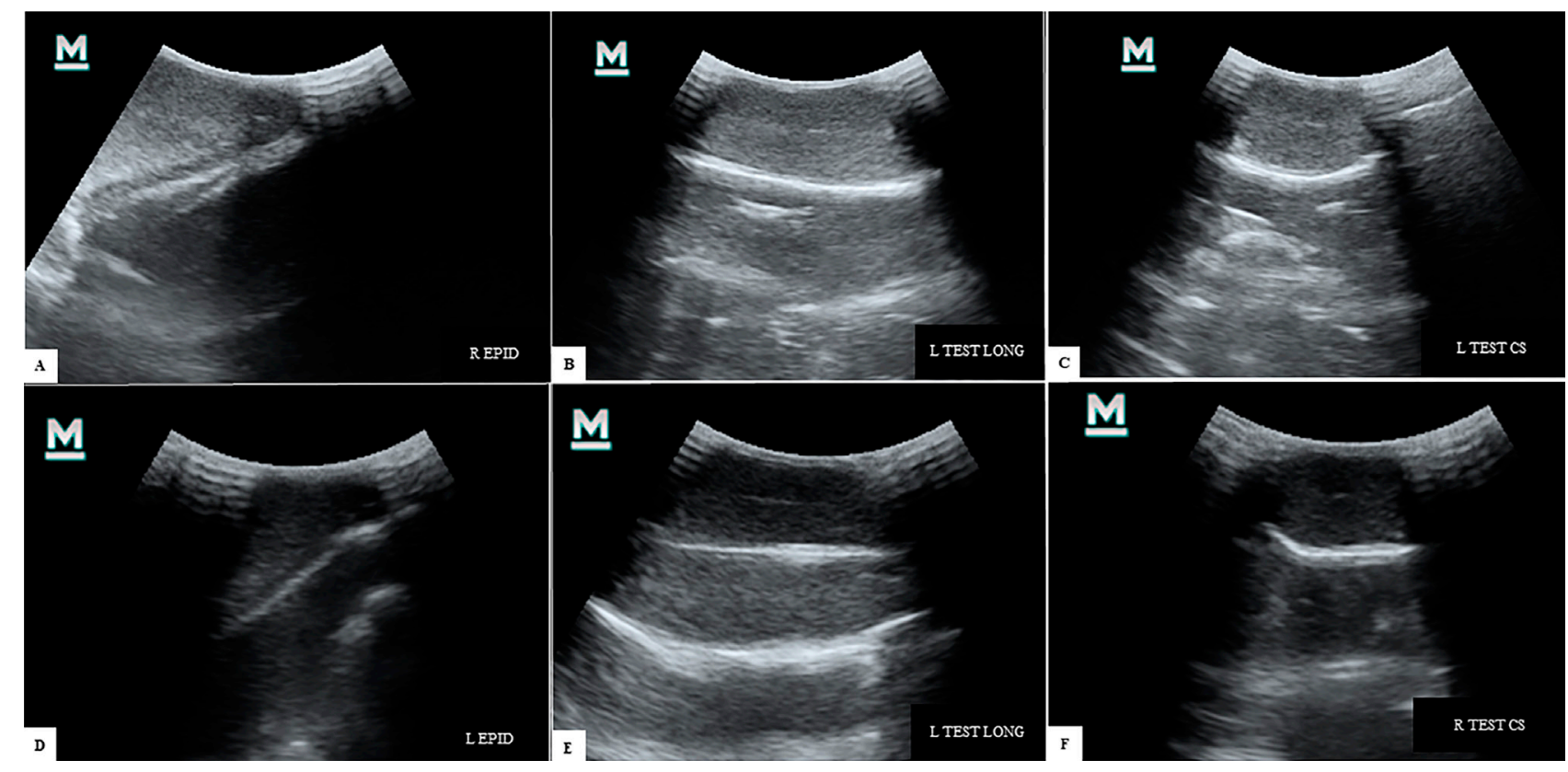

Figure 2. Mode B ultrasonographic images of right (R) or left (L) epididymis (EPID) and testes (TEST) on longitudinal (LONG) or cross-sectional (CS) views. A-C: Images of F+ males. D-F: Images of F- males.

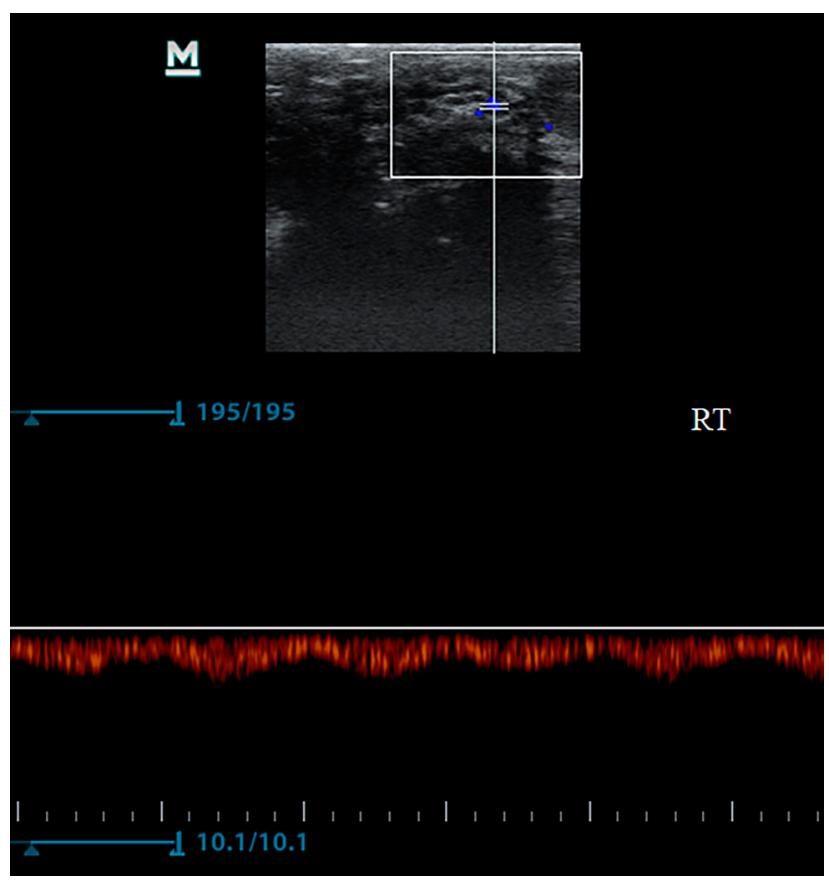

Figure 3. Waveform of supratesticular artery of gray brocket deer (Mazama gouazoubira) using spectral Doppler technique. 
Table 3. Correlations between the ultrasound parameters, scrotal circumference, and testicular volume in gray brocket deer (Mazama gouazoubira).

\begin{tabular}{ccc}
\hline Parameter & Scrotal circumference & Testicular volume \\
\hline PSV $(\mathrm{cm} / \mathrm{s})$ & $\mathrm{r}=0.13, P=0.71$ & $\mathrm{r}=0.33, P=0.32$ \\
EDV $(\mathrm{cm} / \mathrm{s})$ & $\rho=-0.17, P=0.61$ & $\rho=0.16, P=0.63$ \\
TAMAX $(\mathrm{cm} / \mathrm{s})$ & $\rho=-0.20, P=0.56$ & $\rho=0.19, P=0.57$ \\
PI & $\rho=0.22, P=0.51$ & $\rho=0.37, P=0.26$ \\
RI & $\mathrm{r}=0.44, P=0.18$ & $\mathrm{r}=0.46, P=0.15$ \\
NPV (longitudinal testes) & $\mathrm{r}=0.76, \mathrm{P}=0.01^{*}$ & $\mathrm{r}=0.78, P=0.008^{*}$ \\
NPV (cross-sectional testes) & $\mathrm{r}=0.89, P=0.0006^{*}$ & $\mathrm{r}=0.91, P=0.0003^{*}$ \\
NPV (epididymis) & $\mathrm{r}=0.50, P=0.14$ & $\mathrm{r}=0.40, P=0.26$ \\
PSD (longitudinal testes) & $\rho=0.44, P=0.21$ & $\rho=0.59, P=0.07$ \\
PSD (cross-sectional testes) & $\rho=0.80, P=0.0052$ & $\rho=0.82, P=0.004^{*}$ \\
PSD (epididymis) & $\rho=0.14, P=0.70$ & $\rho=0.33, P=0.35$ \\
\hline
\end{tabular}

*Shows significant correlations $(P<0.05)$. $\mathrm{r}=$ Pearson's correlation coefficient; $\rho=$ Spearman's correlation coefficient; $\mathrm{PSV}=$ peak systolic velocity; $\mathrm{EDV}=$ end diastolic velocity; $\mathrm{TAMAX}=$ time-average maximum velocity; $\mathrm{PI}=$ pulsatility index; RI= resistivity index; NPV= numerical pixel values; $\mathrm{PSD}=$ pixel standard deviation.

\section{DISCUSSION}

The present results give basal information on testes and epididymis sonographic appearance, testes perfusion, and testicular size in healthy male gray brocket deers as well as pathological changes associated with azoospermia. To the best of our knowledge, this study is the first to report changes in testicular echogenicity, scrotal circumference, and testicular volume in normospermic and oligo/azoospermic gray brocket deer adult males and to find correlation between these variables.

Scrotal circumference is a simple repeatable method of measuring testicular size which is strongly correlated with testicular weight [35], semen production $[17,45]$ and with fertility [35]. Testicular volume is also a simple method of measuring testes and is also correlated to scrotal circumference [45]. It is positively correlated to sperm motility and morphology and negatively correlated to immature germ cells [14]. In the present study, scrotal circumference and testicular volume measurements were different between normospermic and azoospermic deers. The source of these deer's poor semen quality and decreased testes size is possibly testicular degeneration $[11,28]$ which can be caused by multiple factors such as advanced age, heat, medication (nitrofurans and benzimidazoles), nutritional deficiencies, stress, trauma or corticosteroid therapy [21]. The cause for sperm disturbances was confirmed only in male 6, which presented intense germ cell epithelial degeneration compatible to testicular degeneration in the histopathological analysis.
Unlike what might happen in rams [7], testicular degeneration may not cause noticeable alterations in deer's testes parenchyma using ultrasound subjective evaluation. Similarly, no ultrasound subjective alterations were noted in bulls after scrotal insulation. However, lower mean pixel intensity was also observed in bulls' testes after scrotal insulation, suggesting the occurrence of reduced echogenicity during a degenerative process. Thus, computerized analysis of B mode images may help providing detailed and objective information about subtle changes and have an important role in reproductive assessment [4].

Some factors can influence testicular pixel intensity (NPV), such as age [12,37] and genotype. In bulls, there was an increase in testicular echogenicity (testicular pixel intensity) during sexual development, which is associated with improved testicular growth and cell population expansion [12]. Also, testes NPV were moderately and positively correlated with inner and outer seminiferous tubules diameter in bulls [20], and moderate to strong positive correlations were observed between testes NPV and seminiferous tubules area and lumen in stallions [37]. Thus, it is suggested that the animals in group F- had compromised testicular development and spermatogenesis due to their lower testicular NPV than the ones in group F+. The deer in F+ in the present study presented good seminal concentration and higher values for scrotal circumference and testicular volume. This can also be linked with observations of a previous study in bulls in which pixel intensity showed moderate positive correlations to spermatids percent- 
ages and testis weight [20], meaning that the higher the NPV, the more spermatids are observed and the larger are testes (in a physiological setting).

The F- group had lower testicular volume, NPVs and PSDs in cross-sectional testicular images, suggesting higher protein levels and lower lipid contents were present in their parenchyma and those components account for echogenicity and echotexture of the testicular parenchyma [2].

About pixel heterogeneity, group F+ presented more heterogeneous testes (in cross-sectional view), so higher PSD is associated to a better spermatogenic function. In dogs, more heterogenous testes were associated with higher sperm output [33] and, in stallions, scrotal testes from young males were more heterogenous than retained testes [37]. In addition, testes PSD (obtained through ultrasound evaluation in direct contact with tunica albuginea) was positively correlated to lumen area of seminiferous tubules in rams [22] and stallions [37]. In animals with spermatogenesis imbalance, the cell population is reduced inside seminiferous tubules [11], and their area is decreased too [37]. Hence, it is suggested that a decrease in variation between anechoic and echogenic parenchyma is observed in those males due to decrease in density of seminiferous tubules and consequent cell population reduction inside these tubules.

Scrotal circumference can be moderately associated with testes cell population parameters. In bulls, it was positively correlated to daily sperm production [35] and negatively correlated to the degree of germinal epithelial loss [30], suggesting that changes on seminiferous tubules can affect scrotal circumference measurements and testes echogenicity and echotexture which was corroborated with observations from this study, in which moderate to strong correlations were observed between testes NPV and scrotal circumference.

Scarce literature describes spectral Doppler parameters of testicular artery. RI and PI of testicular artery have been described in domestic animals, such as rams [7], stallions [38] and dogs [43] and in wild animals, such as llamas and alpacas [29]. Discrepancies in RI and PI may be observed amongst males, suggesting spectral Doppler indices are highly variable [7]. Those parameters can be associated with semen quality $[9,27]$. Thus, describing spectral Doppler parameters in gray brocket deer may contribute to establishing reference values for healthy males and aiding in diagnosing vascular disturbs involving testes $[25,34]$ or evaluating if a pre-existing pathology is affecting testicular blood supply [26,34].
In this study, no differences in spectral Doppler parameters were observed between the two groups. Similarly, in fertile and subfertile stallions, there was no difference among blood flow parameters in the supratesticular artery $[34,38]$. On the contrary, in dogs with and without testicular tumor, differences in PSV and TAMAX were observed [26] and, in fertile and infertile dogs, PSV and EDV were different [43]. In camelids, RI showed no difference between fertile and infertile males, but PSV and EDV were higher for fertile males [29]. These different results may be due to different locations of the evaluated vessel, species and techniques. It is known that many factors can influence vascular changes, including age [38], ambient temperature, seasonality $[41,44]$, pathological conditions [34,43], and anaesthesia [8]. Thus, they may have influenced the spectral Doppler parameter's variability in the supratesticular artery of gray brocket deer.

\section{CONCLUSIONS}

In conclusion, changes in testicular tissue in deer with different reproductive status were detectable using testes NPV, scrotal circumference, and testicular volume measurements where lower values were observed in deer with reproductive disruptions. Thus, these techniques can be feasible procedures and good indicators of male reproductive health in gray brocket deer, supporting in male selection for assisted reproduction programs. The correlations between testicular size and testes NPV and PSD can be associated with germ cell population and spermatogenesis; however, further studies are required to confirm this association in the species.

\section{MANUFACTURERS}

${ }^{1}$ Syntec. Santana de Parnaíba, SP, Brazil.

${ }^{2}$ Venco. Londrina, PR, Brazil.

${ }^{3}$ Neovet. Uberaba, MG, Brazil.

${ }^{4}$ Mindray. Darmstadt, DA, Germany.

${ }^{5}$ Wayne Rasband - National Institute of Health. Bethesda, MD, USA. ${ }^{6}$ The R Foundation. Vienna, Austria.

Acknowledgements. The authors would like to thank the AbaYby Conservation Institute - Ecopoint Environmental Education Ltd., and the Claro Commercial Wild Animal Breeding Farm for supplying the animals used in the experiment. We would also like to thank these funding agencies for financial support: FUNCAP (Ceara's Foundation of Scientific and Technologic Development Support), CNPq (National Council for Scientific and Technological Development) and CAPES (Brazilian Federal Agency for the Support and Evaluation of Graduate Education). 
Funding. Research grant: CAPES/Cofecub number 88881.142966/2017-01.

Ethical approval. The study was approved by the Ethics Committee of the State University of Ceará (number 7913746-2017) and by the System of Authorization and Information on Biodiversity - SISBIO (number 60925).
Declaration of interest. The authors declare no conflict of interest. The authors alone are responsible for the content and writing of paper.

\section{REFERENCES}

1 Ahmadi B., Lau C.P.S., Giffin J., Santos N., Hahnel A., Raeside J., Christie H. \& Bartlewski P.M. 2012. Suitability of epididymal and testicular ultrasonography and computerized image analysis for assessment of current and future semen quality in the ram. Experimental Biology and Medicine. 237(2): 186-193.

2 Ahmadi B., Mirshahi A., Giffin J., Oliveira M.E.F., Gao L., Hahnel A. \& Bartlewski P.M. 2013. Preliminary assessment of the quantitative relationships between testicular tissue composition and ultrasonographic image attributes in the ram. Veterinary Journal. 198(1): 282-285.

3 Ali K.M., Ahmad N., Akhtar N., Ali S., Ahmad M. \& Younis M. 2011. Ultrasound imaging of testes and epididymides of normal and infertile breeding bulls. Pakistan Veterinary Journal. 31(4): 345-350.

4 Arteaga A.A., Barth A.D. \& Brito L.F.C. 2005. Relationship between semen quality and pixel-intensity of testicular ultrasonograms after scrotal insulation in beef bulls. Theriogenology. 64(2): 408-415.

5 Barth A.D. \& Waldner C.L. 2002. Factors affecting breeding soundness classification Veterinary Medicine. Canadian Veterinary Journal. 43: 274-284.

6 Bartlewski P.M., Giffin J.L., Oluwole O.A. \& Hahnel A.C. 2017. Prospective ultrasonographic and endocrine predictors of spermatogenic onset in ram lambs. Animal Reproduction Science. 179: 44-48.

7 Batissaco L., Celeghini E.C.C., Pinaffi F.L.V., Oliveira B.M.M., Andrade A.F.C., Recalde E.C.S. \& Fernandes C.B. 2013. Correlations between testicular hemodynamic and sperm characteristics in rams. Brazilian Journal of Veterinary Research and Animal Science. 50(5): 384-395.

8 Baumgartner C., Bollerhey M., Ebner J., Laacke-Singer L., Schuster T. \& Erhardt W. 2010. Effects of ketaminexylazine intravenous bolus injection on cardiovascular function in rabbits. Canadian Journal of Veterinary Research. 74(3): 200-208.

9 Biagiotti G., Cavallini G., Modenini F., Vitali G. \& Gianaroli L. 2002. Spermatogenesis and spectral echo-colour Doppler traces from the main testicular artery. BJU International. 90(9): 903-908.

10 Black-Decima P. \& Vogliotti A. 2016. Mazama gouazoubira. The IUCN Red List of Threatened Species 2016. 56p. e.T29620A22154584. http://dx.doi.org/10.2305

11 Bousmaha F. \& Khoudja F.B. 2012. Comparative and pathological study of the testis and epididymis in rams, bucks and bulls of Algeria. Asian Journal of Animal and Veterinary Advances. 7(10): 950-959.

12 Brito L.F.C., Barth A.D., Wilde R.E. \& Kastelic J.P. 2012. Testicular ultrasonogram pixel intensity during sexual development and its relationship with semen quality, sperm production, and quantitative testicular histology in beef bulls. Theriogenology. 78(1): 69-76.

13 Cheng F., Wu J., Chan J.P., Wang J., Fung H., Colenbrander B. \& Tung K. 2004. The effect of different extenders on post-thaw sperm survival, acrosomal integrity and longevity in cryopreserved semen of Formosan Sika deer and Formosan Sambar deer. Theriogenology. 61(9): 1605-1616.

14 Condorelli R., Calogero A.E. \& La Vignera S. 2013. Relationship between testicular volume and conventional or nonconventional sperm parameters. International Journal of Endocrinology. 2013: 1-7.

15 Costa K.L.C., Matta S.L.P., Gomes M.L.M., Paula T.A.R., Freitas K.M., Carvalho F.A.R., Silveira J.A., Dolder H. \& Mendis-Handagama S.M.L.C. 2011. Histomorphometric evaluation of the neotropical brown brocket deer Mazama gouazoubira testis, with an emphasis on cell population indexes of spermatogenic yield. Animal Reproduction Science. 127(34): 202-212.

16 Cursino M.S. \& Duarte J.M.B. 2016. Using sperm morphometry and multivariate analysis to differentiate species of gray Mazama. Royal Society Open Science. 3(11): 1-9. 
17 Dana N., Tegegne A. \& Shenkoru T. 2000. Feed intake, sperm output and seminal characteristics of Ethiopian highland sheep supplemented with different levels of leucaena (Leucaena leucocephala) leaf hay. Animal Feed Science and Technology. 86: 239-249.

18 Duarte J. \& Garcia J. 1995. Assisted reproduction in brazilian Cervidae. Revista Brasileira de Reprodução Animal. 19(1-2): 111-121.

19 Duguma G., Cloete S.W.P., Schoeman S.J. \& Jordaan G.F. 2002. Genetic parameters of testicular measurements in Merino rams and the influence of scrotal circumference on total flock fertility. South African Journal of Animal Science. 32(2): 76-82.

20 Evans A.C.O., Pierson R.A., Garcia A., McDougall L.M., Hrudka F. \& Rawlings N.C. 1996. Changes in circulating hormone concentrations, testes histology and testes ultrasonography during sexual maturation in beef bulls. Theriogenology. 46(2): 345-357.

21 Foster R.A. 2009. Sistema reprodutivo do macho. In: McGavin M.D. \& Zachary J.F. (Eds). Bases da Patologia em Veterinária. 4.ed. Rio de Janeiro: Elsevier, pp.1317-1348.

22 Giffin J.L., Franks S.E., Rodriguez-Sosa J.R., Hahnel A. \& Bartlewski P.M. 2009. A Study of Morphological and Haemodynamic Determinants of Testicular Echotexture Characteristics in the Ram. Experimental Biology and Medicine. 234(7): 794-801.

23 Goeritz F., Quest M., Wagener A., Fassbender M., Broich A., Hildebrandt T.B., Hofmann R.R. \& Blottner S. 2003. Seasonal timing of sperm production in roe deer: Interrelationship among changes in ejaculate parameters, morphology and function of testis and accessory glands. Theriogenology. 59(7): 1487-1502.

24 Gosch B., Bartolomaeus T. \& Fischer K. 1989. Light and scanning electron microscopy of fallow deer (Dama dama) spermatozoa. Journal of Reproduction and Fertility. 87(1): 187-192.

25 Gumbsch P., Gabler C. \& Holzmann A. 2002. Colour-coded duplex sonography of the testes of dogs. The Veterinary Record. 151(5): 140-145.

26 Günzel-Apel A., Möhrke C. \& Nautrup C. 2001. Colour-coded and pulsed Doppler sonography of the canine testis, epididymis and prostate gland: Physiological and pathological findings. Reproduction in Domestic Animals. 36: 236240.

27 Hedia M.G., El-Belely M.S., Ismail S.T. \& El-Maaty A.M.A. 2019. Monthly changes in testicular blood flow dynamics and their association with testicular volume, plasma steroid hormones profile and semen characteristics in rams. Theriogenology. 123: 68-73.

28 Javed M.T., Khan A. \& Naz N.A. 2001. Studies on abnormal buffalo bulls with reference to scrotal circumference, semen characteristics, seminal plasma hormones and their association with testicular and epididymal histopathology. Veterinarski Arhiv. 71(4): 223-236.

29 Kutzler M., Tyson R., Grimes M. \& Timm K. 2011. Determination of testicular blood flow in camelids using vascular casting and color pulsed-wave doppler ultrasonography. Veterinary Medicine International. 2011(4): 638602.

30 Madrid N., Ott R.S., Veeramachaneni D.N., Parrett D.F., Vanderwert W. \& Willms C.L. 1988. Scrotal circumference, seminal characteristics, and testicular lesions of yearling Angus bulls. American Journal of Veterinary Research. 49(4): 579-585.

31 Martinez-Pastor F., Guerra C., Kaabi M., Garcia-Macias V., Paz P., Alvarez M., Herraez P. \& Anel L. 2005. Season effect on genitalia and epididymal sperm from Iberian red deer, roe deer and Cantabrian chamois. Theriogenology. 63(7): 1857-1875.

32 Monfort S.L., Brown J.L., Bush M., Wood T.C., Wemmer C., Vargas A., Williamson L.R., Montali R.J. \& Wildt D.E. 1993. Circannual inter-relationships among reproductive hormones, gross morphometry, behaviour, ejaculate characteristics and testicular histology in Eld's deer stags (Cervus eldi thamin). Journal of Reproduction and Fertility. 98(2): 471-480.

33 Moxon R., Bright L., Pritchard B., Bowen I.M., Souza M.B., Silva L.D.M. \& England G.C.W. 2015. Digital image analysis of testicular and prostatic ultrasonographic echogencity and heterogeneity in dogs and the relation to semen quality. Animal Reproduction Science. 160: 112-119.

34 Ortiz-Rodriguez J., Anel-Lopez L., Martín-Muñoz P., Álvarez M., Gaitskell-Phillips G., Anel L., RodríguezMedina P., Peña F. \& Ferrusola C. 2017. Pulse Doppler ultrasound as a tool for the diagnosis of chronic testicular dysfunction in stallions. PLOS ONE. 12(5): 1-22. 
35 Palasz A.T., Cates W.F., Barth A.D. \& Mapletoft R.J. 1994. The relationship between scrotal circumference and quantitative testicular traits in yearling beef bulls. Theriogenology. 42(4): 715-726.

36 Pintus E. \& Ros-Santaella J.L. 2014. Assisted reproductive technologies in deer (Artiodactyla, Cervidae): a review. Scientia Agriculturae Bohemica. 45(2): 136-146.

37 Pozor M., Morrissey H., Albanese V., Khouzam N., Deriberprey A., Macpherson M.L. \& Kelleman A.A. 2017. Relationship between echotextural and histomorphometric characteristics of stallion testes. Theriogenology. 99: 134145 .

38 Pozor M.A. \& McDonnell S.M. 2004. Color Doppler ultrasound evaluation of testicular blood flow in stallions. Theriogenology. 61(5): 799-810.

39 Ribeiro M. da S., Quirino C.R., Bartholazzi Junior A. \& Pacheco A. 2017. Biometry and ultrasound evaluation of testicles and accessory glands in Santa Ines rams. Revista Brasileira de Zootecnia. 46(4): 317-323.

40 Rola L.D., Zanetti E.D.S. \& Duarte J.M.B. 2013. Evaluation of semen characteristics of the species Mazama americana in captivity. Animal Production Science. 53(5): 472-477.

41 Samir H., Nyametease P., Nagaoka K. \& Watanabe G. 2018. Effect of seasonality on testicular blood flow as determined by color Doppler ultrasonography and hormonal profiles in Shiba goats. Animal Reproduction Science. 197(October): 185-192. doi: 10.1016/j.anireprosci.2018.08.027.

42 Singh A.K., Brar P.S. \& Cheema R.S. 2014. Relationships among frozen-thawed semen fertility, physical parameters, certain routine sperm characteristics and testosterone in breeding Murrah buffalo ( Bubalus bubalis ) bulls. Veterinary World. 7(9): 644-651.

43 Souza M.B., England G.C.W., Mota Filho A.C., Ackermann C.L., Sousa C.V.S., Carvalho G.G., Silva H.V.R., Pinto J.N., Linhares J.C.S., Oba E. \& Silva L.D.M. 2015. Semen quality, testicular B-mode and Doppler ultrasound, and serum testosterone concentrations in dogs with established infertility. Theriogenology. 84(5): 805-810.

44 Strina A., Corda A., Nieddu S., Solinas G., Lilliu M., Zedda M.T., Pau S. \& Ledda S. 2016. Annual variations in resistive index (RI) of testicular artery, volume measurements and testosterone levels in bucks. Comparative Clinical Pathology. 25(2): 409-413.

45 Ugwu S.O.C. 2009. Relationship between scrotal circumference, in situ testicular measurements and sperm reserves in the West African dwarf bucks. African Journal of Biotechnology. 8(7): 1354-1357.

46 Ungerfeld R., Villagrán M., Lacuesta L., Vazquez N. \& Pérez W. 2017. Asymmetrical size and functionality of the pampas deer (Ozotoceros bezoarticus) testes: Right testis is bigger but left testis is more efficient in spermatogenesis. Journal of Veterinary Medicine Series C: Anatomia Histologia Embryologia. 46(6): 547-551. 